\title{
Loris Malaguzzi, Reggio Emilia and Democratic Alternatives to Early Childhood Education Assessment
}

\author{
GUY ROBERTS-HOLMES
}

\begin{abstract}
This article responds to the dangers arising from baseline assessment in reception classes. It contrasts predictive testing which claims to ascertain each child's ability and potential with the processes of observation, documentation and discussion developed in Reggio Emilia. It explores the two very different understandings of children which they reflect.
\end{abstract}

\section{Introduction}

The Reggio Emilia schools continue to demonstrate that that there are alternatives to the current hegemonic utilitarian approach towards (early childhood) education. They were established by Loris Malaguzzi as a historical and contextually situated response to Mussolini's Fascism and the horrors of the Second World War. The innovative, visionary and democratic Reggio Emilia schools were premised upon Malaguzzi's political and ethical understanding that education should primarily be concerned with creating the democratic conditions in which children can become critical, creative and independent thinkers. Malaguzzi articulated a culturally 'rich' image of the child necessary for such an emancipatory education: 'it is our moral duty to credit children, all children, with resources, possibilities and capacities that are much greater and much more universal than believed ... and as the bearers of rights, values and competencies' (Malaguzzi, cited in Cagliari et al, 2016, p. 377). This understanding of the competent, sociable and democratic child (and teacher) with rights enables the complex narrative assessment known as pedagogical documentation. At its heart, pedagogical documentation is concerned with making learning processes and project work visible, and then subjecting them to democratic deliberation about meaning (potentially including not only 
teachers, but parents, other citizens and children themselves). Such democratic deliberation demands copious quantities of time, institutional support and an openness to joy, awe and the unexpected; not qualities much in evidence today. It tunes in to what the child is interested in and activities that show what they can do. It is open to each child's unpredictability and diversity of potential. Today Malaguzzi's inspirational ideas are widely known and pedagogical documentation has become widespread, well beyond Reggio Emilia.

Second, and in stark contrast, Malaguzzi described the ways in which a negative, demeaning and disrespectful image constructed 'poor' (limited, inadequate and incompetent) children. Such children could be decontextualised, categorised and regulated. They were indistinct children without qualities who stay where you put them and you can describe them as you wish, without gender or role or history' (Malaguzzi, cited in Cagliari et al, 2016, p. 376). All this can be achieved through the simplistic measurement of a basic utilitarian audit-style approach such as reception baseline assessment (DfE, 2014). Bradbury and Roberts-Holmes (2016) reported the widespread and serious misgivings regarding baseline assessment and in particular the inaccurate and potentially damaging algorithmic predictive profiling of children from age 4 to age 11 (Wrigley, 2015). Elsewhere, Bradbury and Roberts-Holmes (2017, forthcoming) argue that reception baseline assessment was primarily concerned with the further regulation, governance and datafication of children, teachers and early education.

\section{The Rich Child and Democratic Potentiality}

Malaguzzi's image of the 'rich child' who has 'one hundred languages' with which to express themselves is open to possibilities, potentialities and alternatives and demands that the teacher engages in an intelligent and sensitive pedagogy of respectful listening. Malaguzzi (cited in Cagliari et al, 2016, p. 379) stated that a teacher must 'vary, multiply, intensify, re-invent and re-listen to children's activities, behaviours, words and languages. Support and make use of their interests, their forms of learning, choosing and communicating.'

Pedagogical documentation centres children's voices and their understandings by making children's learning 'visible' through sharing their creative arts, performance, photography, writing and play. Embarking upon connected interdisciplinary project work chosen and led by young children with the teacher participating as a facilitator, enabler and co-constructor means 'being sensitive to the unpredictable results of children's investigation and research' (Rinaldi, 2005, cited in Moss, 2014). Pedagogical documentation is located within the post-modern paradigm and can embrace diversity, uncertainty, contingency and unpredictable outcomes. Such democratic learning eschews reductionist notions of fixed learning objectives based upon normative targets, goals and expected predetermined outcomes.

An excellent example of pedagogical documentation is 'The Crow Project' in Moss (2014). After a year's work on crows initiated by the children after a 
walk in the local woods, the children and the teachers sit together to discuss their collaborative learning in a process of democratic deliberation together. The documentation consists of children's (and teachers') drawings, paintings, photographs from the woods, research notes and plaster and papier mâché models of crows. The teacher describes the children's learning apparent in the drawings:

The children's drawings look almost like a film, which frame by frame, depicts how their curiosity shapes an ever more powerful relationship with the birds. The birds are no longer unknown entities flying overhead. They became the children's friends. And the children become extremely pleased with themselves when they discover the differences in their pictures over time. By reviewing the earliest documentation together with the children we can observe the children's individual learning process. What is most interesting, however, is how apparent the importance of the group is to the individual in the learning process. (Moss, 2014, pp. 149-150)

The Crow Project had a strong emphasis upon open-ended project work, listening to children and 'a strong belief in the unlimited potentiality of children', and focused upon the learning processes of participation, dialogue and imagination.

\section{Baseline Assessment and the Culturally 'Poor' Incompetent Child}

Baseline assessment, however, with its norm-based criteria which seek to govern and control through its simplistic categories, numbers and linear outcomes, is based upon the image of the culturally 'poor' child. This demands that education, at ever earlier ages, becomes akin to an 'exam factory' (Hutchings, 2015) where children acquire and reproduce pre-determined knowledge as they are readied for the neo-liberal values of the marketplace. Such children require ever-tighter regulation, control and governance if they are to be primary and secondary school ready and able to compete in the DfE's 'global race' (DfE, 2013 , p. 6). Rather than being open to the child's possibilities as a thriving human being, baseline assessment has the tendency to judge children in terms of a unit of potential 'human capital' from age 4 to age 11 . Baseline assessment thus represented what Malaguzzi has termed 'nothing but a ridiculous simplification of knowledge and a robbing of meaning from individual histories' (Malaguzzi, cited in Cagliari et al, 2016, p. 378). The predominant use of questions and micro-tasks developed for use with children in their first six weeks of schooling represented a 'rush to categorise' (Malaguzzi, cited in Cagliari et al, 2016, p. 379) and compounded the negativity of judgement and the sense of 'does this child measure up' to a fixed and predefined norm. 
Malaguzzi noted that such a construction encourages a 'prophetic pedagogy' that is based upon prediction of what children should know and their required outcomes. A prophetic pedagogy:

knows everything beforehand, knows everything that will happen, knows everything, does not have one uncertainty, is absolutely imperturbable... This is something so coarse, so cowardly, so humiliating of teacher's ingenuity, a complete humiliation for children's ingenuity and potential. (Malaguzzi, cited in Cagliari et al, 2016, p. 422)

Here the reduction of a child's complexity to a single figure upon which predictions or 'prophecy' of subsequent development could be calculated was central to Reception Baseline Assessment. Judging young children when they first walk through the reception door at age four on the basis of a battery of simple yes/no statements effectively negates, excludes and 'steals' children's 'one hundred languages'. In the following examples taken from one of the leading providers of baseline assessment, teachers had to judge children 'yes' or 'no'. Of course with such complex statements it all depends upon the context, the social interaction and a vast range of other contigent factors, hence the absurdity of such decontextualised statements.

Characteristics of Effective Learning and PSED [Personal, Social and Emotional Development] Statements (Early Excellence, 2016):

'Thinks of his/her own ideas and different ways of doing things, uses imagination in play.'

'Is able to take turns, accepts the needs of others and is aware of the consequences of their actions.'

'Is able to negotiate with peers, recognise and adapt their behaviour to different situations.'

Specific Areas of Learning and Development: Literacy and Matbs:

'Knows that print carries meaning and knows how to handle books.'

'Links sounds to letters, naming and sounding the letters of the alphabet.'

'Counts at least four objects.'

'Is confident to order and ascribe using numbers 1-20, add and subtract using single digit numbers.'

Using the above statements, a child's individualised baseline score was then crudely calculated by adding up their total score and then dividing this by the total number of statements (47) to generate an overall score of one to five for each child. The calculation excluded contextual variables such as how long the child had been in school, their age, and whether or not English was their first language, as well as the young child's sociable and emotional variables. Hutching's findings on the damaging consequences of accountability upon 
children's well-being and mental health was reflected in Bradbury and RobertsHolmes' (2016) national study of teachers' comments on baseline assessment:

'I feel that the Baseline Assessment has to be completed too early in the year and means that teachers are madly trying to collect evidence, rather than concentrating on the welfare of their new pupils and helping to create a calm and relaxing environment which is vital for a positive start to their school life.' (Teacher quoted in Bradbury \& Roberts-Holmes, 2016)

This is ironic because the development of young children's well-being and the development of their learning dispositions are more important and reliable predictors of later academic achievement than early gains in the narrow skills used as simplistic indicators of fixed 'ability' in literacy and maths. Regarding such fixed notions of 'ability', Malaguzzi noted that 'such claims forget that plasticity is one of the central nervous system's characteristics ... thus declaring its susceptibility to experiences children live' (Malaguzzi, cited in Cagliari et al, 2016 , p. 378). Children whose experience in the early years has instead supported emotional well-being, cognitive development and self-regulation during play may score less well on early academic tests, but evidence indicates that these children show higher achievement benefits in the longer term (Whitebread \& Bingham, 2012). Children in Finland, for example, begin formal schooling around three years later than England's Reception year (increasingly a misnomer, given current pressures). They follow active, play-based provision in their kindergarten years; they go on to out-perform British children in later attainment (Bodrova \& Leong, 2007).

One head teacher in Bradbury \& Roberts-Holmes (2016) noted: 'I think doing any sort of reputable assessment of very young children is dodgy because the children are so young. You know if those children were in Denmark they wouldn't have had to pick up a pencil yet.' Trying to assess children who had not yet sufficiently developed emotionally led to a deficit model of assessment showing what they can't do as opposed to what they can do. This means that the assessment itself provided a negative, inaccurate and detrimental measure: baseline assessment (BA) focused on what the children could not do as opposed to what they could do. 'It's ridiculous. It's not a fair representation of children. Many young children are not yet confident enough to show their new teacher what they can do when put on the spot' (class teacher, quoted in Bradbury \& Roberts-Holmes, 2016).

Unfortunately, however, the strict regulations imposed by the Department for Education (DfE) meant that BA had to be carried out within six weeks of the children starting school regardless of whether the children had yet 'settled' in. No adjustment was allowed for the child's month of birth, despite the common sense, and evidence, that twelve months' difference is enormous at this age (for some, it is a quarter of their lives).

I did have children that were crying and I just couldn't get anything out of them at all because they were too upset to do anything, even 
when I left it later on. Some children just refused or just weren't ready and I know they said you only assess them when they are ready, but some children, well, you got to the point where you had to assess them because it had to be done whether they were ready or not. And obviously then it is not accurate because they weren't at a stage when they wanted to say things. (Class teacher, quoted in Bradbury \& Roberts-Holmes, 2016)

This not only leads to inaccurate data being generated but was ethically inappropriate and potentially damaging for children's developing selfconfidence, self-esteem and learner identity.

Some children looked at me and said 'I can't read' when asked to read parts of the assessment. It was heartbreaking to see their reaction to it and I spent a lot of time reassuring children. (Class teacher, quoted in Bradbury \& Roberts-Holmes, 2016)

Here, BA had the inadvertent potential of demotivating and undermining young children's confidence in their abilities when they had only just started school. BA thus established with pseudo-scientific rigour the setting of low expectations for particular groups of children, including summer-born children and those with English as an additional language and special educational needs. The potential for grouping and labelling children based on BA accountability data is a worrying development, especially given its inaccuracy.

I don't think you should [use it to measure progress], I don't think you can, because they are children and they are not robots, not machines, they are children. You don't know what influences they have got from outside, what is going to happen in those seven years, so I think it is ridiculous. (Class teacher, quoted in Bradbury \& Roberts-Holmes, 2016)

The variation between children and their rates of progress meant that any reductionist and simple correlation between Reception and Key Stage 2 was impossible:

Children's progress is going to be judged against how far they have gone in seven years. Now to my mind that is an almost impossible thing to do because you can't test children at 11 about the same things you were testing them at four. It just doesn't make sense. (Class teacher, quoted in Bradbury \& Roberts-Holmes, 2016)

\section{Refusing Baseline Assessment}

Given the problems with baseline assessment, it was not surprising that at least 3000 head teachers refused to implement the 2015 trial. For example, Dame Alison Peacock, who was a member of the DfE's Commission for Assessment Without Levels and who advised the DfE on teacher training and professional 
development, was perhaps the best-known head teacher who publicly stated: 'We are not doing the baseline.' Peacock's outspoken democratic assertion of the complexity of young children's learning demonstrated that locally based and contextual possibilities and alternatives to BA's reductionist approach were preferable and possible:

Understanding children's thinking and their developing ideas through building and sustaining dialogue is an expert form of teaching that enables high challenge within a richly supportive environment. This is the beauty and the art of early years teaching that cannot be reduced to scores on a page, or to boxes on a tracking screen ... we need to put assessment back in its box; thereby refusing temptation to place labels on children or their teachers.

(Peacock, quoted in Ward, 2015)

Refusing the simplistic and reductionist labelling of BA, Peacock demonstrated through her actions that an apparently dominant, totalising and monolithic accountability regime was in fact contestable. Although at the time BA was voluntary, Peacock's and other head teachers' ethical and political refusal of its dominant 'regime of truth' within a harshly punitive and disciplinary audit culture can be considered as a radical 'caring' for herself, the staff and the children as she refused closure, regulation and labelling. Peacock's and other head teachers' refusal to engage with BA is a demonstration of a 'democratic accountability' that 'is morally and politically situated' (Fielding \& Moss, 2011).

Through embracing ongoing narrative formative assessment for learning (AfL) as a counter-discourse to BA, Peacock enabled a politics of hope, possibilities and alternatives. For Peacock, summative assessment data were simply used as 'a background metric' and not allowed to dominate, dictate and steer pedagogy. Instead of Pupil Progress Review (PPR) meetings being focused on data sheets and prior attainment grids, professional pedagogical conversations occurred that "built knowledge about how to inspire future learning' (Peacock, 2016, p. 105). Central to this dialogic approach to assessment was that children engaged in their own reflective learning. Here the transformation of PPR meetings away from an obsession on numerical data led the way to accountability systems based on 'trust, openness, generosity and professional courage' (Peacock, 2016, p. 105). This approach is in line with Malaguzzi, who noted that images of the culturally 'rich' child equally demand images of the 'rich' teacher, parent, school and community.

\section{Conclusion}

At the time of writing, the DfE is considering a further attempt at the introduction of a baseline assessment (DfE, 2017), this time using an individual tablet-based assessment (DfE, 2017). This article has argued that such a reductionist approach to early childhood education will not only produce inaccurate data but is pedagogically absurd and deeply disrespectful to young 


\section{Guy Roberts-Holmes}

children's multiple expressions, competencies and possibilities. In Malaguzzi's terms, baseline assessment in whatever form it is administered has the tendency towards constraining, limiting and 'robbing' a young child's potentiality and their 'one hundred languages'. Baseline assessment and its image of a culturally 'poor' child tells a quasi-scientific, deficit-based story about the incompetencies of a young child (and by extension, their family) and potentially closes down who and what they might become. The different methods of assessment described in this article assume different images not only of the child, but also of the teacher, and the very different conditions for doing that work.

\section{References}

Bodrova, E. \& Leong, D. (2007) Tools of the Mind: the Vygotskian approach to early childhood education. Upper Saddle River, NJ: Pearson/Merrill Prentice Hall.

Bradbury, A. \& Roberts-Holmes, G. (2016) The Introduction of Reception Baseline Assessment: they are children ... not robots, not machines. London: ATL/NUT.

Bradbury, A. \& Roberts-Holmes, G. (2017, forthcoming) The Datafication of Primary and Early Years Education: playing with numbers. London, Routledge.

Cagliari, P., Castagnetti, M., Giudici, C., Rinaldi, C., Vecchi, V. \& Moss, P. (Eds) (2016) Loris Malaguzzi and the Schools of Reggio Emilia: a selection of his writings and speeches, 1945-1993. London, Routledge.

Department for Education (DfE) (2013) More Great Childcare: raising quality and giving parents more choice. London: Department for Education.

Department for Education (DfE) (2014) Reforming Assessment and Accountability for Primary Schools.

https://www.gov.uk/government/uploads/system/uploads/attachment_data/file /297595/Primary_Accountability_and_Assessment_Consultation_Response.pdf (accessed 11 October 2016).

Department for Education/Standards and Testing Agency (2017) Primary Assessment in England: Government consultation.

https://consult.education.gov.uk/assessment-policy-and-development/primaryassessment/supporting_documents/Primary\%20assessment\%20in\%20England.pdf (accessed 19 May 2017).

Early Excellence (2016) EExBA - R Reception Statement Examples. http://earlyexcellence.com/eexba2016 (accessed 10 February 2017).

Fielding, M. \& Moss, P. (2011) Radical Education and the Common School: a democratic alternative. London: Routledge.

Hutchings, M. (2015) Exam Factories? The Impact of Accountability Measures on Children and Young People. London: National Union of Teachers.

Moss, P. (2014) Transformative Change and Real Utopias in Early Childhood Education: a story of democracy, experimentation and potentiality. London: Routledge.

Peacock, A. (2016) Assessment for Learning without Limits. Milton Keynes: Open University Press.

Ward, H. (2015) Superhead Dame Alison Peacock Snubs Baseline Tests for Four-yearolds, TES. https://www.tes.com/news/school-news/breaking-news/superhead- 
dame-alison-peacock-snubs-baseline-tests-four-year-olds (accessed 23 March 2017).

Whitebread, D. \& Bingham, S. (2012) School Readiness: a critical review of perspectives and evidence. TACTYC Occasional Paper No. 2.

Wrigley, T. (2015) Predicting Children's Potential: baseline tests. https://reclaimingschools.org/2015/06/11/predicting-childrens-potentialbaseline-tests/ (accessed 15 December 2016).

GUY ROBERTS-HOLMES' main research interest is in the role of data and its effects upon primary and early years education pedagogy, curriculum and governance. He coined the term 'the datafication of pedagogy' within early years and primary education to critically analyse the ways in which data are increasingly used to govern, regulate and discipline education. His recent research into reception baseline assessment with Alice Bradbury ('They are Children ... Not Robots, Not Machines', commissioned by the NUT and ATL) was awarded the BERA/SAGE Research Impact Prize 2016. Correspondence: g.roberts-holmes@ucl.ac.uk 
